\title{
Influence of a hydrophobic monomer on the physical and mechanical properties of experimental surface sealants
}

\section{Maria Cecília Caldas GIORGI(a) Amalie Perez VOGT ${ }^{(b)}$ Carina de Jesus CORNETA(b) Marilia Mattar de Amoêdo Campos VELO(c)} Débora Alves Nunes Leite LIMA(b) Giselle Maria Marchi BARON(b) Flávio Henrique Baggio AGUIAR(b)

(a) Universidade Estadual do Amazonas, School of Health Sciences, Manaus, AM, Brazil.

(b) Universidade Estadual de Campinas - Unicamp, Piracicaba Dental School, Department of Restorative Dentistry, Piracicaba, SP, Brazil.

(c) Universidade de São Paulo - USP, Bauru School of Dentistry, Department of Operative Dentistry, Endodontics and Dental Materials, Bauru, SP, Brazil.

Declaration of Interest: The authors certify that they have no commercial or associative interest that represents a conflict of interest in connection with the manuscript.

Corresponding Author:

Marília Mattar de Amoêdo Campos Velo E-mail:mariliavelo@yahoo.com.br

https://doi.org/10.1590/1807-3107bor-2018.vol32.0108

Submitted: April 30, 2018

Accepted for publication: August 20, 2018

Last revision: August 30, 2018
Abstract: This study evaluated the effect of adding the hydrophobic monomer 1,12 dodecanediol dimethacrylate (DDDMA) to experimental sealants with and without thermocycling on degree of conversion (DC), water sorption (WS), water solubility (WSB), color stability $(\Delta \mathrm{E})$, and micro-shear bond strength ( $\mu \mathrm{SBS})$. Five experimental and one commercially available sealant (Bisco - BIS) were tested. The experimental sealants were formulated by mixing different percentages of DDDMA monomers and urethane dimethacrylate (UDMA). The photoinitiator system was composed by camphorquinone (CQ) and tertiary amine 4-ethyl benzoate dimetilamiono (EDBA). Ethanol was used as a solvent. The experimental groups were named sequentially according to the monomeric content (DDDMA/UDMA): S40/40 (40/40), S50/30 (50/30), S60/20 (60/20), S70/10 (70/10) and S80/0 (80/0). Data were analyzed separately by one-way ANOVA, followed by Tukey's test $(\mathrm{p}<0.05)$. The values of DC ranged from $94.59 \%(\mathrm{~S} 40 / 40)$ to $54.02 \%$ $(S 80 / 10)$. BIS showed the highest WS value $(\mathrm{p}<0.05)$ and S40/40, S50/30, $S 60 / 20$ and S80/0 showed the lowest WS values of all tested sealants. WSB values ranged from $7.88 \mu \mathrm{g} / \mathrm{mm}^{3}$ (BIS) to $13.27 \mu \mathrm{g} / \mathrm{mm}^{3}$ (S70/10). The highest $\Delta \mathrm{E}$ value was $11.05 \pm 2.88$ for BIS and the highest $\mu$ SBS value was found for S60/20. No significant difference was observed in bond strength between sealants and bovine enamel after thermocycling. Adding DDDMA to the composition of surface sealants can improve its performance, once the monomer increased the degree of conversion and the color stability.

Keywords: Color; Composite Resins; Detal Restoration Repair.

\section{Introduction}

Composite resin is the most used direct restorative material for anterior and posterior teeth, ${ }^{1,2}$ mainly due to its excellent esthetic properties and because it allows a minimal intervention approach. ${ }^{3}$ Despite improvements in the past years, the longevity and durability of the composite material itself are still questioned. ${ }^{4}$ Due to the polymerization reaction, a volumetric shrinkage occurs that generates stress within the material and a poor seal of the restoration. ${ }^{5}$ The shrinkage stress has been associated to potential clinical problems such as marginal failure, recurrent caries, and dental fracture. ${ }^{6,7}$ 
Therefore, alternative polishing materials, including surface sealant agents, have been developed to fill surface defects and irregularities, prevent microleakage, and improve marginal seal. ${ }^{8}$ However, the effectiveness of sealants is quite controversial. Some studies have suggested that the application of surface sealants effectively decreased microleakage, ${ }^{9,10}$ improved the restoration surface texture, ${ }^{11,12}$ and wear resistance of posterior hybrid composite resins. ${ }^{13}$ On the other hand, some studies reported that the application of surface sealants has no significant advantage. ${ }^{14,15}$

Surface sealants are unfilled low-viscosity resins that are polymerized to fill microstructural defects in the restorations formed during finishing and polishing procedures and the marginal gaps by capillary action. ${ }^{16,17}$ When the external surface of a composite resin restoration is rough or when the access to the restoration for hygiene is limited, the bacterial biofilm accumulation and the risk of both caries and periodontal inflammation increase. ${ }^{18}$ Moreover, a decrease in the gloss and esthetic appearance of the restoration may occur. ${ }^{16}$ In these situations, surface sealants might be indicated.

The effectiveness of surface sealants is directly related to the flow rate and depth of penetration (fluidity) onto the subsurface microstructure prior to polymerization. ${ }^{19,20}$ Sealants composition is mainly based on combined monomers such as Bis-GMA (bisphenol glycidyl dimethacrylate), TEGDMA (triethylene glycol dimethacrylate), THFMA (tetrahydrofurfuryl methacrylate), and UDMA (urethane dimethacrylate). However, even with the known advantages as function of their monomer composition, these agents present hydrophilic properties. Because sealants do not contain filler particles, their use could result in lower physical properties, making restorations more susceptible to wear and water absorption. Consequently, the clinical properties of restorative materials could be also affected by the sealant surface composition.

Therefore, since differences in the chemistry of the sealants may influence their properties, the current study proposed the addition of the 1,12 Dodecanediol dimethacrylate (DDDMA) monomer, which has a hydrophobic nature that increases its molecular mobility, facilitating the diffusion into the substrate. DDDMA is frequently used in biomaterials and dental applications as well as coatings, composites, and sealants. According to the manufactures, it provides fast cure, flexibility, and improves the surface characteristic of its polymer matrix. ${ }^{21}$

Thus, we evaluated in vitro the effect of different concentrations of DDDMA in the physical and mechanical properties of the experimental surface sealants, in terms of degree of conversion (DC), water sorption (WS), water solubility (WSB) of the surface sealants, color stability $(\Delta \mathrm{E})$, and micro-shear bond strength ( $\mu \mathrm{SBS})$, comparing them to a commercial surface sealant. The null hypotheses tested were that: (a) the addition of different DDDMA concentrations would not improve neither the physical nor the mechanical properties of the surface sealant.

\section{Metodology}

\section{Experimental design}

The factors under study were six experimental surface sealants named sequentially according to the monomeric content (DDDMA/UDMA): S40/40 (40/40), S50/30 (50/30), S60/20 (60/20), S70/10 (70/10), S80/0 (80/0), the commercial sealant Biscover (BIS), (Bisco Inc., Schaumburg, IL, USA), and a composite resin (Filtek Z250, 3M-ESPE, St. Paul, MN, USA). The response variables were $\mathrm{DC}$, WS, WSB, and $\mu \mathrm{SBS}$ with and without thermocycling of experimental sealants. The effect on $\Delta \mathrm{E}$ after $24 \mathrm{~h}$ of red wine immersion was also evaluated. Product specifications are presented in Table 1.

\section{Preparation of experimental sealants}

The experimental sealants were formulated by mixing (calculated using molar mass) different percentages of DDDMA monomers and urethane dimethacrylate (UDMA). The photoinitiator system was composed by $1 \mathrm{~mol} \%$ of camphorquinone (CQ) and $2 \mathrm{~mol} \%$ of tertiary amine 4-ethyl benzoate dimetilamiono (EDBA); ethanol was used as a solvent. The composition of all tested material is presented in Table 1. 
Table 1. Materials used in the study according to the composition.

\begin{tabular}{|c|c|c|}
\hline Materials & Manufacturer & Composition \\
\hline S40/40 & -.---.--- & Ethanol, DDDMA (40\%), UDMA (40\%), CQ, EDAB \\
\hline S50/30 & -..--..-- & Ethanol, DDDMA (50\%), UDMA (30\%), CQ, EDAB \\
\hline $\mathrm{S} 60 / 20$ & -.-.-.-- & Ethanol, DDDMA (60\%), UDMA (20\%), CQ, EDAB \\
\hline S70/10 & ----------- & Ethanol, DDDMA (70\%), UDMA (10\%), CQ, EDAB \\
\hline $\mathrm{S} 80 / 0$ & -..--.-- & Ethanol, DDDMA (80\%), CQ, EDAB \\
\hline BIS & Bisco Inc., Schaumburg, USA & Ethoxylated Bis-GMA, urethane acrylate, polyethylenoglycol diacrylate \\
\hline Resin composite Z250 & 3M-ESPE St. Paul, MN, USA & Resin: Bis-GMA, UDMA, Bis-EMA, TEGDMA; Filler (82 wt\%): zirconia/silica (size: 0.01-3 $\mu \mathrm{m}$ ) \\
\hline
\end{tabular}

\section{DC measurements}

The specimens were prepared using silicon molds $(1 \times 2 \times 5 \mathrm{~mm})$ to standardize the amount of material. For the irradiation procedure, the sample was standardized in the center of the light source. The specimens were divided into 6 groups to test all surface sealants $(n=8)$. Photo activation was performed at a standardized distance of $2 \mathrm{~cm}$ from the test material using a LED light source (Valo, Ultradent Products Inc, St Louis, MO, USA) with $1,000 \mathrm{~mW} / \mathrm{cm}^{2}$ for $120 \mathrm{~s}$. This time was determined in our previous studies once lower times have failed. The DC measurements were conducted using a Fourier-transform infrared spectroscope (Spectrum 100 FTIR, PerkinElmer, Waltham, MA, USA) with an attenuated total reflectance (ATR-PerkinElmer, Waltham, MA, USA) accessory.

\section{DC calculation}

DC calculation of the surface sealants was done by comparing the height of particular peaks in the spectra derived from the uncured and cured monomer. The percentage of unreacted carbon was from the peak height ratio of the carbonyl (at 1,710 and 1,730 $\mathrm{cm}^{-1}$ ) and those of aliphatic peak (at 1,636 cm $\mathrm{cm}^{-1}$ ) during the polymerization, in relation to the uncured material.

The percentage DC was calculated for each sample as follows:

$$
\mathrm{DC} \%=\frac{[1-\text { peak height after curing }] \times 100}{\text { Peak height before curing }}
$$

\section{Water sorption and solubility}

This experiment was performed in compliance with ISO 4049:2000 standard specifications (except for the specimen dimensions and curing protocol). After DC analyses, all specimens (n =8) were measured using a digital electronic caliper (Mitutoyo Corporation, Tokyo, Japan). Thickness (four measurements at four equidistant points on the circumference) and diameter (two measurements at right angles) of each specimen were registered and mean values were used to calculate the volume (V) of each specimen (in $\mathrm{mm}^{3}$ ). The disks were stored in desiccators containing silica gel at $37^{\circ} \mathrm{C}$ for $24 \mathrm{~h}$ until constant mass was achieved $\left(m_{1}\right)$ in an analytical balance (Ohaus ${ }^{\circledR}$ Analytical Plus, Parsippany, USA) accurate to $0.001 \mathrm{mg}$. Specimens were then stored in plastic containers with distilled water at $37^{\circ} \mathrm{C}$ for 7 days (water volume was $1.5 \mathrm{~mL}$ per specimen). Samples were again weighted after being carefully wiped with an absorbent paper. When constant weight was obtained (two days without weight change), the water-saturated mass was measured as $m_{2}$. Finally, the specimens were dried again in the desiccator at $37^{\circ} \mathrm{C}$ for 7 days until constant mass was obtained, and their masses were once again determined $\left(m_{3}\right)$. The values for WS and WSB, in micrograms per cubic millimeters, were calculated using the following equations:

$$
\mathrm{WS}=\left(m_{2}-m_{3}\right) / \mathrm{V} ; \mathrm{WSB}(\%)=\left(m_{1}-m_{3}\right) / \mathrm{V}
$$




\section{Color stability test}

Forty-eight disc-shaped specimens $(5 \times 2 \mathrm{~mm})$ were prepared for each composite resin (Filtek Z250) $(\mathrm{n}=8)$. A Teflon metal matrix was filled with the resin and covered with a polyester strip and a glass slide. The samples were then compressed for $10 \mathrm{~s}$ to avoid porosity and to remove the excess. Specimens were light-cured from the surface for 20 seconds, according to manufacturer's recommendations, using a LED light source (Valo, Ultradent, Products Inc, St Louis, USA) with $1000 \mathrm{~mW} / \mathrm{cm}^{2}$. Thereafter, the six different surface sealants were applied directly using a microbrush and the specimens were light-cured for $30 \mathrm{~s}$, according to manufacturers' instruction of the commercial sealant Biscover (Bisco, Inc., Schaumburg, USA) in order to standardize the time for all specimens.

Baseline color was measured according to the CIE L*a*b* color scale (Commission Internationale de I'Eclairage) relative to the standard illuminant D65 over a white background on a reflection spectrophotometer (UV-2450; Shimadzu Corp, Tokyo, Japan). Afterwards, the specimens were individually immersed in vials containing red wine for $24 \mathrm{~h}$. The vials were sealed to prevent evaporation of the wine. $\Delta \mathrm{E}$ (color change) after the staining process was calculated between the color coordinates before (baseline) and after the process as measured in the reflectance mode by applying the formula $\Delta \mathrm{E}=\left[\left(\Delta \mathrm{L}^{*}\right) 2+\left(\Delta \mathrm{a}^{*}\right) 2+\left(\Delta \mathrm{b}^{*}\right)^{2}\right] .{ }^{22}$

\section{Measurement of $\mu$ SBS}

Preparation of the specimens

One hundred twenty enamel specimens were prepared from the buccal surface of bovine incisor crowns, which were freshly extracted and stored in $0.1 \%$ thymol solution $(\mathrm{pH} 7.0)$ at $4^{\circ} \mathrm{C}$. The superficial surface of each specimen was finished with wet 600 -grit silicon carbide paper under running water to produce a standard smear layer. The samples were randomly divided into 12 groups of 10 samples each: six groups $(\mathrm{n}=10)$ were loaded until failure in a Universal testing machine (UTM) (EMIC DL 500, São José dos Pinhais, PR, Brazil) with a crosshead speed of $0.5 \mathrm{~mm} / \mathrm{min}$. The other six groups $(n=10)$ were thermocycled for 1000 cycles of water baths at $5 \pm 2^{\circ} \mathrm{C}$ and $55 \pm 2^{\circ} \mathrm{C}$ with the mean dwell time of 1 min each bath.
The polished enamel surfaces were etched using $37 \%$ phosphoric acid gel (Total Etch 37\%, Ivoclar Vivadent, USA) for $30 \mathrm{~s}$ and air-dried. The prepared enamel surfaces were covered by the tested surface sealants, using a microbrush. The bonding layer was spread out by gentle air blow at a distance of $30 \mathrm{~cm}$ to volatilize the solvent, and a cylindrical tube (height: $1.0 \mathrm{~mm}$; diameter: $1.15 \mathrm{~mm}$ ) was placed on the enamel surface. This thin layer of sealant was applied to stabilize the noodle matrix on the enamel surface; however, this thin layer was not light-cured. Thereafter, the sealant was applied with a syringe of $1 \mathrm{~mL}$ to completely fill a perforated noodle matrix [19], prior to curing for $40 \mathrm{~s}$ using a LED light source (Valo, Ultradent, Products Inc, St Louis, MO, USA) with $1000 \mathrm{~mW} / \mathrm{cm}^{2}$. The samples were stored in a steam incubator at $37^{\circ} \mathrm{C}$ and $100 \%$ moisture for $24 \mathrm{~h}$. Afterwards, each sample was immersed in water for 30 min to remove the matrix and the specimens were loaded until failure in UTM as mentioned above.

\section{Statistical Analysis}

Data were statistically analyzed using the software SAS (V 9.3, Cary, NC, EUA). DC, WS, WSB, $\triangle$ E data were subjected to one-way ANOVA ( $\mathrm{p} \leq 0.05)$ followed by Tukey's test $(p<0.05)$ for individual comparisons. $\mu$ SBS data were logarithm 10 transformed and subjected to two-way ANOVA $(\mathrm{p} \leq 0.05)$ followed by Tukey's test $(p<0.05)$ (termocycling $X$ sealant).

\section{Results}

For the DC tests, as seen in Table 2, S40/40, S50/30, $S 60 / 20$, and S70/10 showed higher values without significant difference among them. The lowest value was found for S80/0. The control group (BIS commercial sealant) showed higher WS value $(p<0.05)$ and S40/40, S50/30, S60/20, and S80/0 showed the lowest WS values of all tested sealants (Table 2).

With respect to WSB test, the highest value was found for S70/10, while the lowest value was found for BIS. The experimental sealants S40/40, S50/30, $S 60 / 20$ and $580 / 0$ showed intermediary values of WSB and did not present significant difference among them $(\mathrm{p}>0.05)$. 
Table 2 shows the results from $\Delta \mathrm{E}$. The highest value was $11.05 \pm 2.88$ for BIS, with significant difference from all sealants tested, except to $S 40 / 40$. The sealant S80/0 showed the smallest color shift. The standard $\Delta \mathrm{E}$ $<3.3$ was considered clinically acceptable. ${ }^{22}$ Therefore, all tested materials showed an unacceptable color shift once they presented $\Delta \mathrm{E}>3.3 .^{23}$

Regarding $\mu$ SBS, the specimens treated with BIS and S80/0 were eliminated from the analyses because they presented high number of pre-tests failures. A series of conditions and preliminary studies were conducted and the light-curing protocol was altered, increasing the photo-activation time from 40 to $120 \mathrm{~s}$. However, this was not enough to eliminate such failures. A summary of $\mu$ SBS means is shown in Table 3. For all sealants tested, the values of $\mu$ SBS were lower in the thermocycled groups.

\section{Discussion}

This study aimed to compare the physical and mechanical properties of experimental surface sealants. Based in our results, we rejected the null hypothesis, as the addition of the monomer DDDMA influenced the composition of the experimental sealants.

Overall, the commercial sealant BIS showed an inferior DC than the experimental tested sealants (Table 2). $S 40 / 40, S 50 / 30$, and $S 60 / 20$ showed the highest DC (up 89\%). As the concentration of TEGDMA increases, such as in the commercial sealant, the conversion rate decreased, mainly due to greater cyclization with higher TEGDMA content. ${ }^{24}$ In addition, once our experimental sealants had UDMA in their mixtures, they presented more reactivity and mobility resulting a higher conversion. ${ }^{24}$ This could explain the high monomer conversion of the experimental sealants. The sealant S80/0 showed inferior DC values than the other experimental sealants (Table 2), showing that an exclusive use of DDDMA is not appropriate.

According to our results, the commercial sealant (BIS) showed the highest WS value $(p<0.05)$ once it contained higher levels of UDMA monomers with hydrophilic character. On the other hand, the experimental sealants S40/40, S50/30, S60/20, and S80/0 showed the lowest WS values (Table 2) due to the presence of DDDMA with hydrophobic character.

The highest value for WSB was found for S70/10, while the lowest was found for BIS. The addition of DDDMA and consequent reduction of UDMA to a $60 / 20$ proportion (S40/40, S50/30, and S60/20) and the use of a sealant without UDMA (S80/0) resulted in intermediate values of WSB. Although the commercial sealant showed the highest WS value, it presented the lowest WSB value. Similarly, although the lowest WS value was observed in the S40/40, S50/30, and

Table 3. Average micro-shear bond strength ( $\mu \mathrm{SBS}$ ) values in the experimental groups, according to the different conditions (with or without thermocycling).

\begin{tabular}{lcc}
\hline Groups & $\begin{array}{c}\text { Without thermocycling } \\
(\mathrm{Mpa})\end{array}$ & $\begin{array}{c}\text { With thermocycling } \\
(\mathrm{Mpa})\end{array}$ \\
\hline $\mathrm{S} 40 / 40$ & $3.73 \pm 0.5^{\mathrm{aA}}$ & $3.25 \pm 0.6^{\mathrm{bA}}$ \\
$\mathrm{S} 50 / 30$ & $3.56 \pm 0.7^{\mathrm{aB}}$ & $3.31 \pm 0.9^{\mathrm{bA}}$ \\
$\mathrm{S} 60 / 20$ & $3.75 \pm 1.1^{\mathrm{aA}}$ & $3.25 \pm 0.9^{\mathrm{bA}}$ \\
$\mathrm{S} 70 / 10$ & $3.67 \pm 1.0^{\mathrm{aAB}}$ & $3.36 \pm 0.8^{\mathrm{bA}}$ \\
\hline
\end{tabular}

Distinct lower case letters indicate statistically significant differences $(p<0.05)$ among the columns within each group; Distinct upper case letter indicates statistically significant differences $(p<0.05)$ among the groups within each column.

Table 2. Mean ( \pm Standard Deviation; SD) of degree of conversion (DC), water sorption (WS) and water solubility (WSB), according to the groups.

\begin{tabular}{lcccc}
\hline Sealants & DC (\%) & WS $\left(\mu \mathrm{g} / \mathrm{mm}^{3}\right)$ & WSB $\left(\mu \mathrm{g} / \mathrm{mm}^{3}\right)$ & $\Delta \mathrm{E}$ \\
\hline S40/40 & $94.59 \pm 1.40^{\mathrm{A}}$ & $11.99 \pm 0.63^{\mathrm{C}}$ & $11.82 \pm 0.31^{\mathrm{B}}$ & $8.56 \pm 2.54^{\mathrm{AB}}$ \\
$\mathrm{S} 50 / 30$ & $95.87 \pm 3.9^{\mathrm{A}}$ & $11.71 \pm 0.66^{\mathrm{C}}$ & $11.57 \pm 0.63^{\mathrm{B}}$ & $7.31 \pm 1.58^{\mathrm{B}}$ \\
$\mathrm{S} 60 / 20$ & $94.11 \pm 4.12^{\mathrm{A}}$ & $12.14 \pm 0.41^{\mathrm{C}}$ & $12.05 \pm 0.39^{\mathrm{B}}$ & $7.09 \pm 1.45^{\mathrm{B}}$ \\
$\mathrm{S} 70 / 10$ & $92.25 \pm 4.69^{\mathrm{A}}$ & $13.35 \pm 0.57^{\mathrm{B}}$ & $13.27 \pm 0.46^{\mathrm{A}}$ & $7.14 \pm 1.23^{\mathrm{B}}$ \\
S80/0 & $54.02 \pm 3.68^{\mathrm{C}}$ & $11.20 \pm 0.6^{\mathrm{C}}$ & $11.22 \pm 0.62^{\mathrm{B}}$ & $6.72 \pm 0.77^{\mathrm{B}}$ \\
BIS & $72.89 \pm 5.57^{\mathrm{B}}$ & $14.63 \pm 0.59^{\mathrm{A}}$ & $7.88 \pm 0.36^{\mathrm{C}}$ & $11.05 \pm 2.88^{\mathrm{A}}$ \\
\hline
\end{tabular}

Groups with different uppercase letters (column: comparison among sealants) are significantly different $(p<0.05)$. 
S60/20 sealants, they presented intermediate values of WSB. A correlation between WS and WSB values was expected, since the solvent needs to penetrate the material to lixiviate the unreacted monomers. ${ }^{25}$ In the experimental sealants, the high molecular weight monomers (present in the commercial sealant) were replaced by DDDMA, which favor the solubility of the monomer. The lower molecular weight of DDDMA facilitates its solubility, even showing lower sorption. All WSB values were higher than that provided by ISO 4049 standard $\left(7.5 \mu \mathrm{g} / \mathrm{mm}^{3}\right)$.

In relation to optical properties, the addition of DDDMA monomer increased the hydrophobic character of the surface sealant, which might result in an increased color stability. Our results confirmed this hypothesis since the sealants with higher content of DDDMA showed lower color shift and the commercial sealant showed higher color shift. However, the discoloration of all sealants tested was considered clinically unacceptable $(\Delta \mathrm{E}>3.3) .{ }^{23}$ This is probably related to the fact that, unlike the restorative composites, surface sealants do not contain filler particles. Filler particles are generally inert and should not absorb fluids and colorants; the uptake is dependent on the resin content of the material. In addition, the presence of more hydrophilic monomers in resin sealants compared with composite resins might also explain the decreased color stability. ${ }^{26}$ Therefore, the use of a surface sealant with DDDMA content confirms the superiority of sealant agents in improving the texture of the composite resin surface, showing great properties, since sealants with hydrophobic character showed better color stability. It is important to note that the experimental sealants presented lower $\Delta \mathrm{E}$ values than the commercial ones $(p<0.05)$ and the high color shift of all tested materials could be attributed to the harsh staining protocol, in which an extremely challenge was simulated. Efforts are still necessary in the search of a material with adequate color stability. On the other hand, because all tested materials had an unacceptable color shift, including the commercial sealant, we suggest the use of surface sealants only for posterior teeth.

To evaluate the efficacy and durability of the sealants tested, the bond strength with bovine enamel was analyzed. The use of sealants directly influences the efficacy of the seal and reduces debonding, especially considering the humid environment and the thermal challenges in the oral cavity. Evaluating the bond strength using the $\mu$ SBS test has advantages such as balanced distribution of stress, evaluation in smaller surfaces, reduction of the effect of enamel defects, and recognition of even small differences in bond strength increasing reliability. ${ }^{27}$ However, during the preparation of the specimens, there was a high number of pre-tests failures in all the specimens treated with the S80/0 and the commercial sealant BIS (control group), with the union breaking during the removal of the matrix. In 2016, Vieira et al. ${ }^{28}$ compared three types of matrixes, concluding that the matrix type does not affect the results of bond strength by $\mu$ SBS and the noodle matrix used in our study was the most effective for this procedure. ${ }^{28}$ Maybe the matrix with $1.0 \mathrm{~mm}$ height did not allow the adequate polymerization of S80/0 and BIS, causing the adhesive failure.

Table 3 shows a significant interaction between thermocycling $x$ sealants. When the specimens were not subjected to thermocycling, high value of $\mu$ SBS were found for S60/20. However, when the specimens were subjected to thermocycling, no significant difference in the bond strength among the surface sealants and substrate was observed. Thus, the behavior of the experimental sealants was similar after thermocycling, which equaled their performances. This was because DDDMA is a hydrophobic monomer, which improves the mechanical properties of the material and decreases the degradation of the adhesive interface. However, not being a filled material, the sealant will not provide an increase on the mechanical properties. Its contribution is mainly related to an immediate marginal sealing and smoothing of surface defects. Therefore, a long-term high performance of restorations with the use of surface sealants might be possible, but further studies should be conducted to ensure the effects and confirm the use of surface sealants in clinical practice. Moreover, the unsatisfactory performance of the S80/0 suggests that the exclusive use of the DDDMA monomer is not adequate as a dental material. 


\section{Conclusions}

In summary, the addition of novel monomers in dental materials seems to be promising. Although the addition of DDDMA monomer increased the degree of conversion, it was associated with a decrease in water sorption. The color stability was better with the presence of DDDMA; the sealants S40/40, S50/30, and S60/20

\section{References}

1. Correa MB, Peres MA, Peres KG, Horta BL, Barros AD, Demarco FF. Amalgam or composite resin? Factors influencing the choice of restorative material. J Dent. 2012 Sep;40(9):70310. https://doi.org/10.1016/i.jdent.2012.04.020

2. Nascimento GG, Correa MB, Opdam N, Demarco FF. Do clinical experience time and postgraduate training influence the choice of materials for posterior restorations? Results of a survey with Brazilian general dentists. Braz Dent J. 2013 Nov-Dec;24(6):642-6. https://doi.org/10.1590/0103-6440201302361

3. Demarco FF, Collares K, Correa MB, Cenci MS, Moraes RR, Opdam NJ. Should my composite restorations last forever? Why are they failing? Braz Oral Res. 2017 Aug;31(31 suppl 1):e56.

4. Ferracane JL, Hilton TJ. Polymerization stress: is it clinically meaningful? Dent Mater. 2016 Jan;32(1):1-10. https://doi.org/10.1016/j.dental.2015.06.020

5. Ferracane JL. Resin composite: state of the art. Dent Mater. 2011 Jan;27(1):29-38. https://doi.org/10.1016/i.dental.2010.10.020

6. Mondelli RF, Velo MM, Gonçalves RS, Tostes BO, Ishikiriama SK, Bombonatti JF. Influence of composite resin volume and $\mathrm{C}$-factor on the polymerization shrinkage stress. Braz Dent Sci. 2016;19(2):72-81. https://doi.org/10.14295/bds.2016.v19i2.1257

7. Demarco FF, Corrêa MB, Cenci MS, Moraes RR, Opdam NJ. Longevity of posterior composite restorations: not only a matter of materials. Dent Mater. 2012 Jan;28(1):87-101. https://doi.org/10.1016/i.dental.2011.09.003

8. Ergücü Z, Türkün LS, Aladag A. Color stability of nanocomposites polished with one-step systems. Oper Dent. 2008 Jul-Aug;33(4):413-20. https://doi.org/10.2341/07-107

9. Owens BM, Johnson WW. Effect of new generation surface sealants on the marginal permeability of Class $\checkmark$ resin composite restorations. Oper Dent. 2006 JulAug;31(4):481-8. https://doi.org/10.2341/05-77

10. Lima AF, Soares GP, Vasconcellos PH, Ambrosano GM, Marchi GM, Lovadino JR et al. Effect of surface sealants on microleakage of Class II restorations after thermocycling and long-term water storage. J Adhes Dent. 2011 Jun;13(3):249-54. Https://doi.org/10.3290/i.jad.a19242 showed a better performance. Therefore, further studies should be conducted to test the effect of DDDMA on the properties of adhesive systems and to determine formulations more suitable for clinical practice.

\section{Acknowledgments}

We thank FAPESP (São Paulo Research Foundation; Process 2013/17868-3 and 2013/25376-3).
11. Catelan A, Briso AL, Sundfeld RH, Goiato MC, Santos $\mathrm{PH}$. Color stability of sealed composite resin restorative materials after ultraviolet artificial aging and immersion in staining solutions. J Prosthet Dent. 2011 Apr;105(4):236-41. https://doi.org/10.1016/S0022-3913(11)60038-3

12. Dede DO, Şahin O, Koroglu A, Yilmaz B. Effect of sealant agents on the color stability and surface roughness of nanohybrid composite resins. J Prosthet Dent. 2016 Jul;116(1):119-28. https://doi.org/10.1016/i.prosdent.2015.11.024

13. Dickinson GL, Leinfelder KF. Assessing the longterm effect of a surface penetrating sealant. J Am Dent Assoc. 1993 Jul;124(7):68-72. https://doi.org/10.14219/jada.archive.1993.0265

14. Takeuchi CY, Orbegoso Flores VH, Palma Dibb RG, Panzeri $H$, Lara EH, Dinelli W. Assessing the surface roughness of a posterior resin composite: effect of surface sealing. Oper Dent. 2003 May-Jun;28(3):281-6.

15. Lee YK, Powers JM. Combined effects of staining substances on resin composites before and after surface sealant application. J Mater Sci Mater Med. 2007 May;18(5):685-91. https://doi.org/10.1007/s10856-006-0011-3

16. O'Brien WJ, Johnston WM, Fanian F, Lambert

S. The surface roughness and gloss of composites. J Dent Res. 1984 May;63(5):685-8. https://doi.org/10.1177/00220345840630051601

17. D'Alpino PH, Pereira JC, Rueggeberg FA, Svizero NR, Miyake $\mathrm{K}$, Pashley DH. Efficacy of composite surface sealers in sealing cavosurface marginal gaps. J Dent. 2006 Mar;34(3):252-9. https://doi.org/10.1016/i.jdent.2005.06.010

18. Bollen CM, Lambrechts P, Quirynen M. Comparison of surface roughness of oral hard materials to the threshold surface roughness for bacterial plaque retention: a review of the literature. Dent Mater. 1997 Jul;13(4):258-69. https://doi.org/10.1016/S0109-5641(97)80038-3

19. Torstenson B, Brännström M, Mattsson B. A new method for sealing composite resin contraction gaps in lined cavities. J Dent Res. 1985 Mar;64(3):450-3. https://doi.org/10.1177/00220345850640031201 
20. Reid JS, Saunders WP, Chen YY. The effect of bonding agent and fissure sealant on microleakage of composite resin restorations. Quintessence Int. 1991 Apr;22(4):295-8. P

21. Esstech Inc. Esstech products. Essington: Esstech; 2018 [cited 2018 May 18]. Available from: http://catalog.esstechinc. $\mathrm{com} /$ viewitems/difunctional-monomers/1-12-dodecanedioldimethacrylate

22. Vichi A, Ferrari M, Davidson CL. Color and opacity variations in three different resin-based composite products after water aging. Dent Mater. 2004 Jul;20(6):530-4. https://doi.org/10.1016/j.dental.2002.11.001

23. Ruyter IE, Nilner K, Moller B. Color stability of dental composite resin materials for crown and bridge veneers. Dent Mater. 1987 Oct;3(5):246-51. https://doi.org/10.1016/S0109-5641(87)80081-7

24. Gonçalves F, Pfeifer CC, Stansbury JW, Newman SM, Braga RR. Influence of matrix composition on polymerization stress development of experimental composites. Dent Mater. 2010 Jul;26(7):697-703. https://doi.org/10.1016/i.dental.2010.03.014

25. Floyd CJ, Dickens SH. Network structure of Bis-GMA- and UDMA-based resin systems. Dent Mater. 2006 Dec;22(12):11439. https://doi.org/10.1016/i.dental.2005.10.009

26. Valentini F, Oliveira SG, Guimarães GZ, Barbosa RP, Moraes RR. Effect of surface sealant on the color stability of composite resin restorations. Braz Dent J. 2011;22(5):365-8. https://doi.org/10.1590/S0103-64402011000500003

27. Placido E, Meira JB, Lima RG, Muench A, Souza RM, Ballester RY. Shear versus micro-shear bond strength test: a finite element stress analysis. Dent Mater. 2007 Sep;23(9):1086-92. https://doi.org/10.1016/j.dental.2006.10.002

28. Vieira HH, Catelan A, Lima DANL, Aguiar FHB, Giorgi MCC, Paulillo LAM. Lovadino JR, Influence of matrix type on microshear bond strength test. Dent Cadmos. 2016;84(5):3148. https://doi.org/10.1016/S0011-8524(16)30066-6 